\title{
Eating disorder symptoms: association with perfectionism traits in male adolescents
}

\author{
Leonardo de Sousa Fortes 1,2, Flávia Marcele Cipriani², Sebastião de Sousa Almeida3, Maria Elisa Caputo Ferreira²
}

1 Federal University of Pernambuco (UFPE), Núcleo de Educação Física e Ciências do Esporte, Vitória de Santo Antão, PE, Brazil.

2 Federal University of Juiz de Fora (UFJF), Institute of Human Sciences, Postgraduate Program in Psychology, Juiz de Fora, MG, Brazil.

${ }^{3}$ Faculty of Philosophy, Sciences and Literature of Ribeirão Preto, University of São Paulo (FFCLRP/USP), Ribeirão Preto, SP, Brazil.

Received: 7/24/2013 - Accepted: 8/24/2014

DOl: 10.1590/0101-60830000000024

\begin{abstract}
Background: Evidence indicates a relationship between perfectionism and eating disorder symptoms (EDS). However, there is no such empirical evidence in Brazilian scientific literature. Moreover, studies of EDS in the male sex are scarce. Objective: To analyze a possible association between EDS and perfectionism traits in adolescent males. Methods: Participants were 368 adolescents aged 12 to 15 years. We used the subscales of the Eating Attitudes Test (EAT-26) and the Multidimensional Perfectionism Scale to assess EDS and perfectionism traits, respectively. Results: The results indicated a statistically significant association between the high perfectionism trait and $\operatorname{EDS}\left(X^{2}=16.40\right.$; Wald $\left.=15.92 ; p=0.001\right)$. Moreover, the findings showed no difference in the scores of the Diet $\left(F_{(1,367)}=2.14 ; p=0.23\right)$ or Concern for Food and Bulimia $\left(F_{(1,367)}=2.44 ; p=0.19\right)$ subscales according to groups of perfectionism. However, we identified a higher score on the Oral Self-Control subscale of the EAT-26 in the group with high perfectionism trait than adolescents with a low perfectionism trait $\left(F_{(1,367)}\right.$ $=13.88 ; p=0.02)$. Discussion: EDS were associated with perfectionism in adolescent males.
\end{abstract}

Fortes LS et al. / Arch Clin Psychiatry. 2014;41(5):117-20

Keywords: Eating disorders, perfectionism, adolescents.

\section{Introduction}

Eating disorder symptoms are characterized by eating behaviors that lead to deleterious health, such as food restriction for long periods, self-induced vomiting, the use of laxatives/diuretics to reduce body weight, strenuous physical activity, and the use of anabolic androgenic steroids to gain muscle mass ${ }^{1,2}$. These symptoms are part of the diagnostic criteria for eating disorders such as anorexia nervosa and bulimia nervosa ${ }^{3}$. Evidence indicates that approximately $30 \%$ of adolescents have eating disorder symptoms ${ }^{4-6}$. More specifically, approximately $20 \%$ of adolescent males are affected by these symptoms 7,8 . Although studies are scarce, it is usually considered that the male population is at low risk for the onset of eating disorders ${ }^{2,7}$.

According to Fortes et al. ${ }^{8}$, several factors may be related to eating disorder symptoms, including body composition, ethnicity, economic status, gender, age, and mood, among others. However, some researchers have noted that the symptoms for these disorders may be associated with personality traits, such as perfectionism ${ }^{9,10}$. This, in turn, is characterized by having high standards, being critical in assessing their own behavior, having feelings of failure and believing that people evaluate rigorously ${ }^{11}$. Studies suggest that patients with a clinical diagnosis of an eating disorder may demonstrate high perfectionistic traits 3,12 , which indicates the importance of investigating the association between perfectionism and eating disorder symptoms in adolescents.

During adolescence, a phase comprised of 10 to 19 years of age $^{13}$, muscle mass increases and body fat percentage decreases in males ${ }^{14}$, which is in accordance with current morphological patterns in Western culture ${ }^{15,16}$. However, many teenagers have deviated from this standard physical development due to a sedentary lifestyle and poor food consumption? ${ }^{7}$. Considering that adolescence is critical to the process of personality development ${ }^{11}$ and that young people routinely feel charged by sociocultural agents (parents, friends and media) to have a muscular build ${ }^{8}$, they may have an increased risk for developing high traits of perfectionism.

Despite evidence that indicates the association between perfectionism and eating disorder symptoms ${ }^{15-18}$, no nationwide investigation has been found on this topic. Some studies have shown increased vulnerability to eating disorders in perfectionists compared to nonperfectionists ${ }^{15-18}$. However, it is noteworthy that according to some authors ${ }^{19}$, there are cultural differences regarding the emphasis on body type between different geographical locations, which can lead young people to have an increased or attenuated frequency of adopting eating disorder symptoms. Thus, although research in other countries $^{15-18}$ has indicated a positive relationship between perfectionism and eating disorder symptoms, there is a possibility that this association may not be true for the Brazilian context. Moreover, it is worth noting that much of this research was performed exclusively with women ${ }^{15,18}$. Thus, little attention has been given to males in studies of eating disorder symptoms ${ }^{7,8,20,21}$. Given the above arguments, the aim of this study was to analyze a possible association between eating disorder symptoms and traits of perfectionism in adolescent males.

Therefore, some assumptions were made based on what the scientific literature has advocated ${ }^{9}: 1$ ) Adolescents with high perfectionistic traits are more likely to experience eating disorder symptoms, and 2) youth with high perfectionistic traits show a higher frequency of food restriction and perception of environmental forces that stimulate food intake.

From a practical standpoint, if there is evidence of a positive relationship between perfectionism and eating disorder symptoms in adolescent males, future young people found to have perfectionistic traits may be referred to have a follow-up with a psychologist to prevent the development of an eating disorder.

\section{Methods}

\section{Procedure}

The directors of eleven schools (six public and five private) were invited to participate in the study after being informed about the objectives and procedures. However, only eight of these (four private and four public) agreed to release students to participate in the data collection. Upon authorization from the directors of the schools, meetings with each of the classes were held to explain the objectives and procedures of the study. Informed consent forms (ICF) were delivered to the teens, and they were asked to return them duly signed by their guardians the following week to confirm their voluntary participation.

The survey was conducted in two stages. In the first step, the students completed the instruments Eating Attitudes Test (EAT26), Multidimensional Perfectionism Scale (MPS) and Body Shape Questionnaire (BSQ). This step was performed in a group by a single 
researcher with standardized verbal explanations. Then, after completing the survey, students were individually sent to a room next for anthropometric measurements (weight, height and skinfold).

This study was approved by the Research Ethics Committee in Humans of the Federal University of Juiz de Fora (2282.022.2011 protocol) according to law 466/12 of the National Health Council.

\section{Sample}

This was cross-sectional and school-based study conducted in 2012 in the city of Juiz de Fora/MG with male adolescents aged 12 to 15 years.

According to information from the Department of Education of Juiz de Fora, the population of male adolescents aged 12 to 15 years enrolled in schools in the city in 2011 was approximately 32,000 . Thus, the sample size calculation was performed using the following criteria, following the recommendations of Alves et al.22: a 30\% prevalence for eating disorder symptoms, aligned with the findings of Fortes et al. 7 , 95\% confidence, 5\% sampling error and 1.2 for the purpose of design, totaling 321 students who should be evaluated for the sample, which was representative of the population.

The proportional sample was stratified according to the location of the schools in the geographic regions of the partner city of Juiz de Fora (north, south and center) and the type of school (public and private), and then, children were selected from elementary schools. The random selection occurred through simple drawings in two steps. First was the draw of schools in each region, followed by the draw of adolescents in these units. The schools were selected taking advantage of the link provided by the statistical section of the Education Department of the State of Minas Gerais. The final sample of the survey drew from eight different sampling sites (schools) and consisted of male adolescents who were randomly selected and were present in schools on days of collection.

Only the youth who presented the ICF signed by a guardian and who were enrolled in elementary school in the city of Juiz de Fora/ MG in 2012 were included in the survey.

The study included 404 children, 36 of whom excluded for not answering the questionnaire completely or not participating in anthropometric assessments. Thus, the final sample was 368 adolescents.

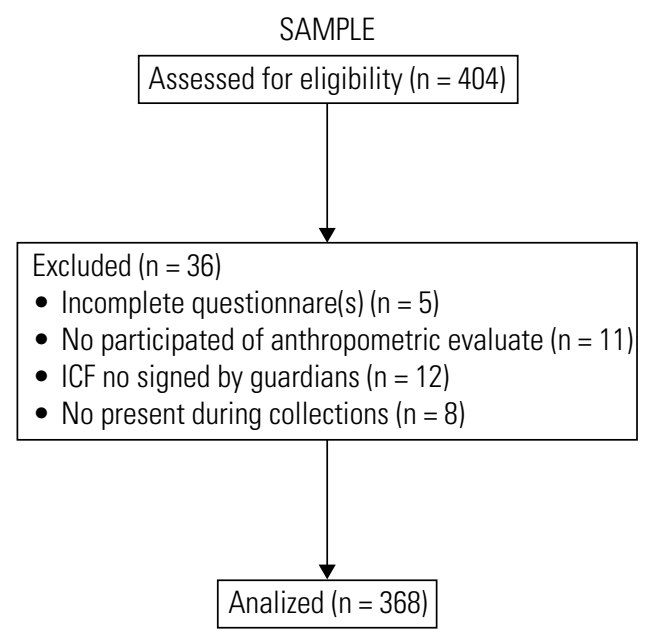

Figure 1. Flowchart of sample recruitment.

\section{Instruments}

To assess eating disorder symptoms, the EAT- $26^{23}$ was administered. The EAT-26 was validated by Fortes et al. ${ }^{24}$ for Brazilian male adolescents. The questionnaire consists of 26 questions divided into three factors: 1) diet, which relates to the pathological refusal of foods with high calories and concern for physical appearance; 2) bulimia and preoccupation with food, which refers to episodes of binge eating followed by purging behaviors for loss/weight control; and 3) oral self-control, which reflects self-control in relation to food and evaluates the dietary intake of stimulants environmental and social forces. The participant has six response options for each item ranging from 0 (rarely, almost never, and never) to 3 (always). The only question that presents scores in reverse order is question 25. The score of the EAT-26 is calculated by summing its items. When the total is greater than or equal to 20, the presence of symptoms of the eating disorder is positive (EAT+). In the validation study, Fortes et al. ${ }^{24}$ showed an internal consistency of 0.87 . For the present sample, the value of the internal consistency was 0.89 , assessed by Cronbach's alpha.

Perfectionism was assessed by the MPS25, validated for Portuguese by Soares et al. ${ }^{11}$. The scale consists of 45 items that seek to evaluate traces of behaviors related to perfectionism. The issues of MPS are arranged in a Likert scale and range from 1 (completely disagree) to 7 (completely agree), divided into three dimensions: 1) self-oriented perfectionism, which involves related cognitions and behaviors, demanding self-assessments, and motivation to pursue perfection and to avoid failure; 2 ) socially prescribed perfectionism, i.e., the need to meet the standards prescribed by others and the belief that people evaluate rigorously and exert pressure for them to meet perfect expectations; and 3) other-oriented perfectionism, which refers to the beliefs and expectations regarding the capabilities and performance of others. The total score can range from 45 to 315. A higher score indicates greater perfectionist behavior, and vice versa. Because of the data analysis, we considered adolescents with scores equal to or greater than 153.00 (50 percentile) with high perfectionism (MPS+). The test revealed a Cronbach's alpha internal consistency of 0.81 for the MPS.

Body dissatisfaction was assessed by the BSQ ${ }^{26}$. The BSQ is a self-report instrument that consists of 34 questions in a Likert scale format, ranging from $1=$ never to $6=$ always. The questionnaire seeks to assess the frequency of concern or dissatisfaction that the respondent has with his weight and physical appearance, or his body dissatisfaction. A higher score indicates a greater depreciation of their body appearance satisfaction, and vice versa. This questionnaire has been validated for the Brazilian adolescent population ${ }^{27}$. For the present sample, the internal consistency was calculated with Cronbach's alpha, yielding a value of 0.94 . Considering that body dissatisfaction can influence eating disorder symptoms ${ }^{8}$, it was decided to control the BSQ scores in the statistical analyses.

Body mass was measured using a portable Tanita brand digital scale with $100 \mathrm{~g}$ precision and a maximum capacity of $200 \mathrm{~kg}$. We used a portable stadiometer, accurate to $0.1 \mathrm{~cm}$ with a maximum height of $2.20 \mathrm{~m}$ Welmy mark, to measure the height of the participants. The body mass index (BMI) was obtained using the calculation BMI = body mass $(\mathrm{kg}) /$ height $\left(\mathrm{m}^{2}\right)$. Because some studies have demonstrated the influence of BMI on eating disorder symptoms ${ }^{6,7}$, it was decided to control for the BMI in the statistical analyses.

To calculate participants' percentage of body fat, the protocol developed by Slaughter et al. ${ }^{28}$ was used. The triceps and subscapular skinfolds were measured according to the standardization determined by the International Society for Advancement for Kineanthropometry $^{29}$, using a Lange ${ }^{\circledR}$ brand compass (caliper; Cambridge Scientific Industries Inc.) with a precision of $1 \mathrm{~mm}$. The measurements were made in rotational form and collected three times with the mean values. Given the findings of some investigations that indicate the influence of body fat on eating disorder symptoms ${ }^{5,8}$, the percentage of fat was controlled for in the statistical analyses.

\section{Statistical analysis}

The Kolmogorov-Smirnov test was administered to evaluate the distribution of the study variables. Due to the parametric non-violation of the EAT-26 scores and MPS, we used measures of central tendency (mean), dispersion (standard deviation, standard error, minimum and maximum) and relative frequency to describe the variables of 
the research. A binary logistic regression was conducted to analyze the dichotomous classifications provided for MPS (MPS $\geq 153.00$ ) and EAT-26 (EAT $\geq 20)$. A multivariate analysis of covariance (MANCOVA) was used to compare the scores of the subscales of the EAT-26 as function of dichotomous classifications provided for MPS. The post hoc Bonferroni test was applied to identify possible significant differences. Finally, we calculated the effect size, represented by the letters "d", to highlight the importance of differences in the practical point of view. All data were analyzed using SPSS 17.0 software, adopting a significance level of $5 \%$.

\section{Results}

The results indicated that $19.02 \%$ and $49.4 \%$ of adolescents showed eating disorder symptoms (EAT+) and high trait perfectionism (MPS+), respectively. Descriptive data for all variables in this study can be seen in table 1 .

Table 1. Descriptive values for the study

\begin{tabular}{|l|c|c|c|c|}
\hline Variable & Minimum & Maximum & Mean & SD \\
\hline EAT-26 & 0 & 63 & 13.77 & 9.44 \\
\hline MPS & 80 & 261 & 142.09 & 28.93 \\
\hline BSQ & 34 & 162 & 71.55 & 19.67 \\
\hline BMI $\left(\mathrm{kg} / \mathrm{m}^{2}\right)$ & 15.33 & 38.49 & 21.52 & 0.78 \\
\hline$\%$ BF & 4.19 & 41.28 & 20.11 & 2.05 \\
\hline Age (years) & 12 & 15 & 13.80 & 0.83 \\
\hline
\end{tabular}

SD: standard deviation; EAT-26: Eating Attitudes Test; MPS: Multidimensional Perfectionism Scale; BSQ: Body Shape Questionnaire; BMI: body mass index; \%BF: percentage of body fat.

The logistic regression model described in table 2, revealed a statistically significant association between high trait perfectionism $(\mathrm{MPS}+)$ and eating disorder symptoms $\left(\mathrm{EAT}+; X^{2}=15.87\right.$, Wald $=$ $15.04, p=0.001$ ). Participants with scores equal to or higher than 153.00 in MPS demonstrated a $92 \%$ likelihood for the most eating disorder symptoms (EAT+) when compared to adolescents with lower scores.

Table 2. Odds ratio for eating disorder symptoms (reference category: EAT-26 $\geq 20$ ) in male adolescents based on the MPS ratings

\begin{tabular}{|l|c|c|c|}
\hline Variable & Classification & OR & Cl (95\%) \\
\hline Perfectionism* & MPS- $(<153.00)$ & 1.00 & - \\
\hline & MPS+ $(\geq 153.00)$ & 1.92 & $1.49-5.71$ \\
\hline
\end{tabular}

EAT-26: Eating Attitudes Test; MPS: Multidimensional Perfectionism Scale; OR: odds ratio; $\mathrm{Cl}$ : confidence interval; ${ }^{*} \mathrm{p}<0.05$.

The multivariate analysis of covariance showed no differences in the scores of the subscales Diet $\left(F_{(1,367)}=2.09, p=0.22, d=0.1\right)$ or Bulimia and Food Preoccupation $\left(F_{(1,367)}=2.31, p=0.20, d=\right.$ 0.2 ) between the perfectionism groups (Table 3). However, the post hoc Bonferroni test showed higher scores on the subscale Oral SelfControl in the group with high trait perfectionist (MPS+) when compared to adolescents with low trait perfectionism $\left(F_{(1,367)}=13.96\right.$, $p=0.01, d=0.5$ ), as shown in table 3 .

Table 3. Comparison the scores of the subscales of the EAT-26 for each of the groups of perfectionism in adolescent males

\begin{tabular}{|l|c|c|c|}
\hline Variable & \multicolumn{2}{|c|}{ Group } & $p$ value \\
\hline Perfectionism & Low (MPS $<153,00)$ & High (MPS $\geq 153.00)$ & \\
\hline \multicolumn{4}{|c|}{ Mean (SE) } \\
\hline Diet & $4.92( \pm 0.82)$ & $5.14( \pm 1.11)$ & $\leq 0.22$ \\
\hline $\begin{array}{l}\text { Bulimia and food } \\
\text { preoccupation }\end{array}$ & $2.22( \pm 0.64)$ & $2.38( \pm 0.73)$ & $\leq 0.20$ \\
\hline Oral self-control & $1.70( \pm 1.06)$ & $4.58( \pm 1.41)$ & $\leq 0.01$ \\
\hline
\end{tabular}

SE: standard error; MPS: Multidimensional Perfectionism Scale.

\section{Discussion}

This research aimed to examine a possible association between eating disorder symptoms and traits of perfectionism in adolescent males. Evidence has indicated that there is a relationship between eating disorder symptoms and perfectionism, which is considered one of the personality traits related to eating disorder symptoms ${ }^{15-18}$. However, to date, no concrete evidence was presented in Brazilian literature. It is also worth noting that the studies on males related to factors associated with eating disorder symptoms are scarce ${ }^{7,8}$.

The findings of this study indicated a prevalence of $19.02 \%$ for eating disorder symptoms. Although there is little data in the literature regarding the prevalence of these symptoms in young males ${ }^{7,8}$, it seems that the frequency of male eating behaviors that lead to deleterious health has increased in recent years ${ }^{21}$. Studies have pointed to the media as being responsible for this fact ${ }^{2}$. According to Rodgers et al. ${ }^{20}$, television and magazines often show male models with very high body muscularity, which reflects the desire of adolescent boys to conform to the cultural aesthetic standards, resulting in some cases in the onset of eating disorder symptoms.

The results concerning perfectionism indicated a statistically significant association with eating disorder symptoms. Boys with a high standard of perfectionism showed a greater chance of eating disorder symptoms compared to boys with low perfectionistic traits. This result corroborates findings of other studies using females ${ }^{15-18}$. It seems that the drive for perfection, fear of failure and the belief that people evaluate rigorously feelings considered typical of perfectionist people are associated with eating disorder symptoms ${ }^{10}$. Perhaps young people with high perfectionistic traits have beliefs that their morphological remodeling may facilitate social acceptance or optimize their "status" within a group of friends. To that end, perfectionist teens use food restriction, the auto-induction of vomiting, strenuous physical activity, use of laxatives/diuretics and/or anabolic steroids as strategies to gain/reduce body weight/ muscle mass ${ }^{21}$.

Regarding the comparison of eating disorder symptoms between the perfectionism groups, the findings showed differences only for the Oral Self-control subscale of the EAT-26. These results indicated that dietary restriction, binge eating and purging behaviors were similar between adolescents with a high and low perfectionism trait, partially corroborating with the assumptions made in the introduction. However, these results are contrary to the findings of research conducted with females ${ }^{15-18}$. In fact, perfectionist male adolescents routinely aspire to remain thin and have bulging muscles ${ }^{11}$, which is contrary to binge eating because this behavior usually induces a brief increase in body weight ${ }^{12}$. However, it was expected that food restriction, considered a behavior aimed at reducing body weight, was more common in young people with high perfectionistic traits. Perhaps male adolescents' desire to have a greater volume/muscle size ${ }^{7}$ explains the less frequent occurrence of food restriction, even in subjects with a high standard of perfectionism.

On the other hand, young people with high perfectionistic traits showed greater oral self-control over food and a greater perception that they were pressed for food intake when compared to adolescents with low perfectionistic traits, corroborating the hypotheses stated earlier in this article and findings of other studies on females ${ }^{16,18}$. Aligned with Filaire et al. ${ }^{9}$, perfectionistic people often show high concern for others' opinions about their diet, which explains some of the above findings. Furthermore, Rouveix et al. ${ }^{10}$ note that perfectionist subjects may present accentuated rigor in the types of food they will consume in a meal due to the fear of fattening and not meeting current cultural aesthetic standards.

Although this study has revealed interesting and novel results for the national literature, is has some limitations that should be highlighted. Researchers note that young people cannot respond reliably to questionnaires ${ }^{5,21}$. However, Fortes et al. ${ }^{8}$ note that in studies with large samples, the self-report instruments can be considered the "gold standard" method because it is easy to apply and 
has low operating costs. Also noteworthy is the use of the doubly indirect method to estimate body fat in adolescents. However, we emphasize the difficulty of access to sophisticated equipment and the large financial outlay in the use of these devices. Another limitation was the cross-sectional design, which made it impossible to make an inference of causality. This means that there is no way to assess the intensity and the direction of the associations found between the study outcomes and the independent variables. Additionally, MPS has not been validated for the target population of this study, which represents an important limitation. However, there are no instruments to measure the same construct that have been validated in this population. Finally, it is believed that this is the first study to be conducted in Brazil that studies the relationship between eating disorder symptoms and perfectionism in adolescent males.

Research results showed that the eating disorder symptoms were associated with perfectionism in adolescent males who were students in the city of Juiz de Fora/MG. Considering this finding, the adolescent males who have perfectionist traits in their behavior in schools and are found to be perfectionists by psychometric instruments, for example, MPS, may be vulnerable to the adoption of eating behaviors that are deleterious to health (restricting food, vomiting and using laxatives/diuretics). However, it should be noted that more research is needed to confirm the positive relationship between perfectionism and eating disorder symptoms in males.

The researchers recommend, therefore, future investigations with longitudinal characteristics regarding behavioral variables among adolescents of both sexes. These surveys would enable the advancement of scientific knowledge in this area and allow for more appropriate interventions to reduce the prevalence of eating disorder symptoms in this population.

\section{References}

1. Leal GVS, Philippi ST, Polacow VO, Cordás TA, Alvarenga MS. O que é comportamento de risco para transtornos alimentares em adolescentes? J Bras Psiquiatr. 2013;62(1):62-75.

2. Alvarenga MS, Scagliusi FB, Philippi ST. Comportamento de risco para transtorno alimentar em universitárias brasileiras. Rev Psiq Clín. 2011;38(1):3-7

3. Bernardi F, Harb ABC, Levandovski RM, Hidalgo MPL. Transtornos alimentares e padrão circadiano alimentar: uma revisão. Rev Psiquiatr Rio Gd Sul. 209;31(3):170-6.

4. Sampei MA, Singulem DM, Novo NF, Juliano Y, Colugnati FAB. Atitudes alimentares e imagem corporal em meninas adolescentes de ascendência nipônica e caucasiana em São Paulo (SP). J Pediatr (Rio J). 2009;85(2):122-8.

5. Scherer FC, Martins CR, Pelegrini A, Matheus SC, Petroski EL. Imagem corporal em adolescentes: associação com a maturação sexual e sintomas de transtornos alimentares. J Bras Psiquiatr. 2010;59(3):198-202.

6. Martins CR, Pelegrini A, Matheus SC, Petroski EL. Insatisfação com a imagem corporal e a relação com estado nutricional, adiposidade corporal e sintomas de anorexia e bulimia em adolescentes. Rev Psiquiatr Rio Gd Sul. 2010;32(1):19-23.

7. Fortes LS, Amaral ACS, Almeida SS, Ferreira MEC. Efeitos de variáveis psicológicas, morfológicas e sociodemográficas sobre o comportamento alimentar de adolescentes. Rev Paul Ped. 2013;31(2):182-8.

8. Fortes LS, Morgado FFR, Ferreira MEC. Fatores associados ao comportamento alimentar inadequado em adolescentes escolares. Rev Psiq Clín. 2013;40(2):59-64.
9. Filaire E, Rouveix M, Pannafieux C, Ferrand C. Eating attitudes, perfectionism and body-esteem of elite male judoists and cyclists. J Sports Sci Med. 2007;6(1):50-7.

10. Rouveix M, Bouget M, Pannafieux C, Champely S, Filaire E. Eating attitudes, body esteem, perfectionism and anxiety of judo athletes and nonathletes. Int J Sports Med. 2007;28(2):340-5.

11. Soares MJ, Gomes AA, Macedo AF, Azevedo MHP. Escala Multidimensional de Perfeccionismo: adaptação portuguesa. Rev Port Psicossom. 2003;5(1):46-55.

12. Teixeira PC, Costa RF, Matsudo SM, Cordás TA. Physical exercises in patients with eating disorders. Rev Psiq Clín. 2009;36(4):145-52.

13. World Health Organization. Development of a WHO growth reference for school-aged children and adolescents. Bull World Health Org. 2007;85(9):660-7.

14. Fortes LS, Almeida SS, Ferreira MEC. Processo maturacional, insatisfação corporal e comportamento alimentar inadequado em jovens atletas. Rev Nutr. 2012;5(5):575-86.

15. Brown AJ, Parman KM, Rudat DA, Craighead LW. Disordered eating, perfectionism, and food rules. Eat Behav. 2012;13(4):347-53.

16. Lichtenstein MB, Christiansen E, Elklit A, Bilenberg N, Støving RK. Exercise addiction: a study of eating disorder symptoms, quality of life, personality traits and attachment styles. Psychiatry Res. 2014;215(2):410-6.

17. Boone L, Soenens B, Vansteenkiste M, Braet C. Is there a perfectionist in each of us? An experimental study on perfectionism and eating disorder symptoms. Appetite. 2012;59(2):531-40.

18. Dickie L, Wilson M, McDowall J, Surgenor LJ. What components of perfectionism predict drive for thinness? Eat Disord. 2012;20(3):232-47.

19. Laus MF, Miranda VPN, Almeida SS, Costa TMB, Ferreira MEC. Geographic location, sex and nutritional status play an important role in body image concerns among Brazilian adolescents. J Health Psychol. 2013;18(3):332-8.

20. Rodgers R, Cabrol H, Paxton SJ. An exploration of the tripartite influence model of body dissatisfaction and disordered eating among Australian and French college women. Body Image. 2011;8(1):208-15.

21. Smith AR, Hawkeswood SE, Bodell LP, Joiner TE. Muscularity versus leanness: an examination of body ideals and predictors of disordered eating in heterosexual and gay college students. Body Image. 2011;8(2):232-6.

22. Alves E, Vasconcelos FAG, Calvo MCM, Neves J. Prevalence of symptoms of anorexia nervosa and dissatisfaction with body image in female adolescents in Florianópolis, Santa Catarina, Brazil. Cad Saude Publica. 2008;24(3):503-12.

23. Garner DM, Olmsted MP, Bohr Y, Garfinkel PA. The eating attitudes test: psychometric features and clinical correlations. Psychol Med. 1982;12(1):871-8.

24. Fortes LS, Amaral ACS, Conti MA, Cordás TA, Ferreira MEC. Qualidades psicométricas do Eating Attitudes Test (EAT-26) para a população adolescente masculina brasileira. Psicol Refl Crít. (no prelo).

25. Hewitt PL, Flett GL. Perfectionism in the self and social contexts: conceptualization, assessment, and association with psychopathology. J Pers Soc Psychol. 1991;60(3):456-70.

26. Cooper PJ, Taylor M, Cooper Z, Fairburn CG. The development and validation of the Body Shape Questionnaire. Int J Eat Disord. 1987;6(3):485-94.

27. Conti MA, Cordás TA, Latorre MRDO. Estudo de validade e confiabilidade da versão brasileira do Body Shape Questionnaire (BSQ) para adolescentes. Rev Bras Saúde Mater Infant. 2009;9(3):331-8.

28. Slaughter MH, Lohman TG, Boileau R, Hoswill CA, Stillman RJ, Yanloan $\mathrm{MD}$, et al. Skinfold equations for estimation of body fatness in children and youth. Hum Biol. 1988;60(5):709-23.

29. ISAK - The International Society for Advancement for Kinanthropometry. First printed. Australia: National Library of Australia; 2001. 